\title{
Decadal fluctuations in the western Pacific recorded by long precipitation records in Taiwan
}

\author{
Wan-Ru Huang ${ }^{1}$ (D) S.-Y. Simon Wang ${ }^{2,3} \cdot$ Biing T. Guan ${ }^{4}$
}

Received: 10 November 2016 / Accepted: 22 April 2017 / Published online: 27 April 2017

(c) The Author(s) 2017. This article is an open access publication

\begin{abstract}
A 110-year precipitation record in Taiwan, located at the western edge of the subtropical North Pacific, depicts a pronounced quasi-decadal oscillation (QDO). The QDO in Taiwan exhibits a fluctuating relationship with the similar decadal variations of sea surface temperature (SST) anomalies in the central equatorial Pacific, known as the Pacific QDO. A regime change was observed around 1960, such that the decadal variation of Taiwan's precipitation became more synchronized with the Pacific QDO's coupled evolutions of SST and atmospheric circulation than before, while the underlying pattern of the Pacific QOD did not change. Using long-term reanalysis data and CMIP5 single-forcing experiments, the presented analysis suggests that increased SST in the subtropical western Pacific and the strengthened western extension of the North Pacific subtropical anticyclone may have collectively enhanced the relationship between the Taiwan precipitation and the Pacific QDO. This finding provides possible clues to similar regime changes in quasi-decadal variability observed around the western Pacific rim.
\end{abstract}

Electronic supplementary material The online version of this article (doi:10.1007/s00382-017-3707-9) contains supplementary material, which is available to authorized users.

Wan-Ru Huang

wrhuang@ntnu.edu.tw

1 Department of Earth Sciences, National Taiwan Normal University, No. 88, Sec. 4, Tingchou Rd., Taipei 11677 , Taiwan, ROC

2 Utah Climate Center, Utah State University, Logan, UT, USA

3 Department of Plants, Soils, and Climate, Utah State University, Logan, UT, USA

4 School of Forestry and Resource Conservation, National Taiwan University, Taipei, Taiwan, ROC
Keywords Precipitation · Taiwan · Pacific quasi-decadal oscillation $\cdot$ Subtropical anticyclone

\section{Introduction}

Interannual variability characterizes the climate of the Asian-Pacific region, making seasonal prediction difficult (Fan et al. 2012; Lu et al. 2013; Zhao and Yang 2014; Sun and Wang 2015). In addition to the interannual variability, the climate in the Asian-Pacific region also fluctuates with a prominent frequency of 10- to 20-years, referred to as quasi-decadal oscillation (QDO) (Hsu and Chen 2011; Wang et al. 2011; Li and Zhou 2014; Li et al. 2015). Located in the northwestern Pacific, near the East Asian continent (Fig. 1a), the climate in Taiwan also exhibits a noticeable QDO influence. Since the early 1960s, the warm season (July-October) rainfall in Taiwan has experienced a marked 10- to 20-year variation (Fig. 1b) (Hsu and Chen 2011). Similar QDO signals were observed in the number of occurrences of tropical cyclones affecting Taiwan (Fig. 1c) (Chan 2008; Chen et al. 2013; Hung 2013) and in the frequency of summer diurnal rainfall events (Fig. 1d) (Huang et al. 2015). Apparently, the QDO is a predominant mode of variability in both the seasonal precipitation and weather systems of Taiwan, even though previous research (Hsu and Chen 2011; Huang et al. 2015) noted that the QDO in the western Pacific only became apparent after the 1960s.

The Pacific QDO describes the coupled evolution of sea surface temperature (SST) and atmospheric circulation at the 10- to 20-year timescale (Li 1998; White and Liu 2008; Wang et al. 2011); its variations in the tropical Western Pacific can serve as precursors of tropical cyclone threats (Wang and Clark 2011). In Taiwan, 
Fig. 1 a Location of Taiwan with shaded topography. b July to October (JASO) precipitation averaged over Taiwan; c October to December (OND) tropical cyclone (TC) frequency in the vicinity of Taiwan (averaged over $\left.115^{\circ}-125^{\circ} \mathrm{E}, 20^{\circ}-30^{\circ} \mathrm{N}\right)$; d June to August (JJA) convective afternoon rainfall (CAR) frequency in Taiwan, adopted from Huang and Chen (2015); e Annual rainfall in Taiwan from 5 hundred-year-stations (TP for Taipei, TC for Taichung, TN for Tainan, HC for Hengchun and TT for Taitung), with record from 1901 onwards and site locations given in (a). The original time series are shaded, while the 10- to 20-year bandpass filter is indicated by the thick red lines. The post-1960 period, as used in (b-d), is outlined in (e). f Power spectrum of the Taiwan precipitation index overlaid by the $95 \%$ confidence interval computed from autoregressive red noise; the quasi-decadal frequency band is highlighted (a) Taiwan \& 5 stations

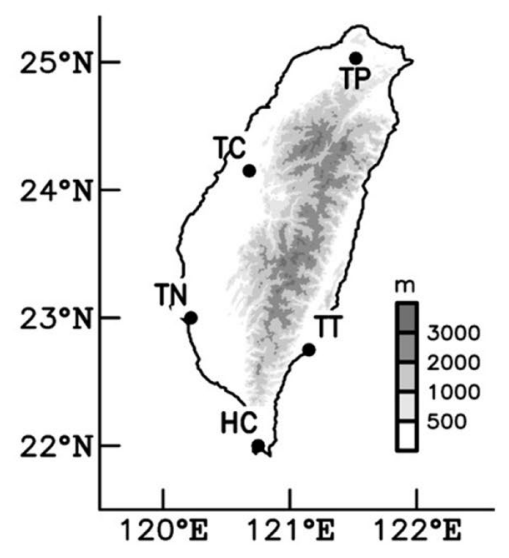

(f) Power spectrum of (e)

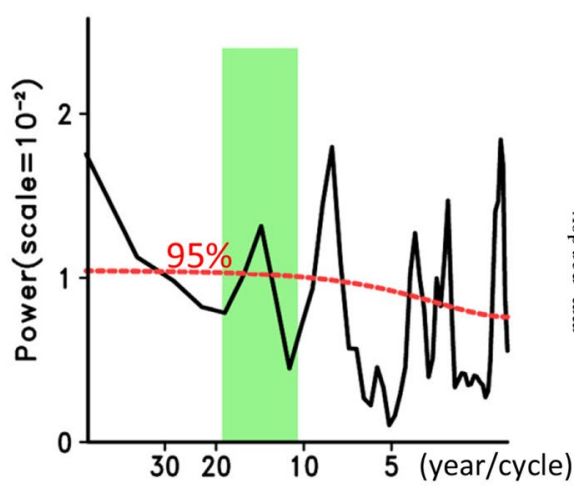

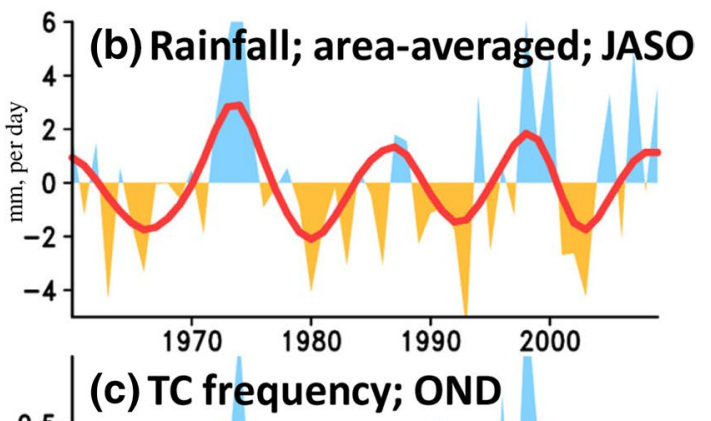
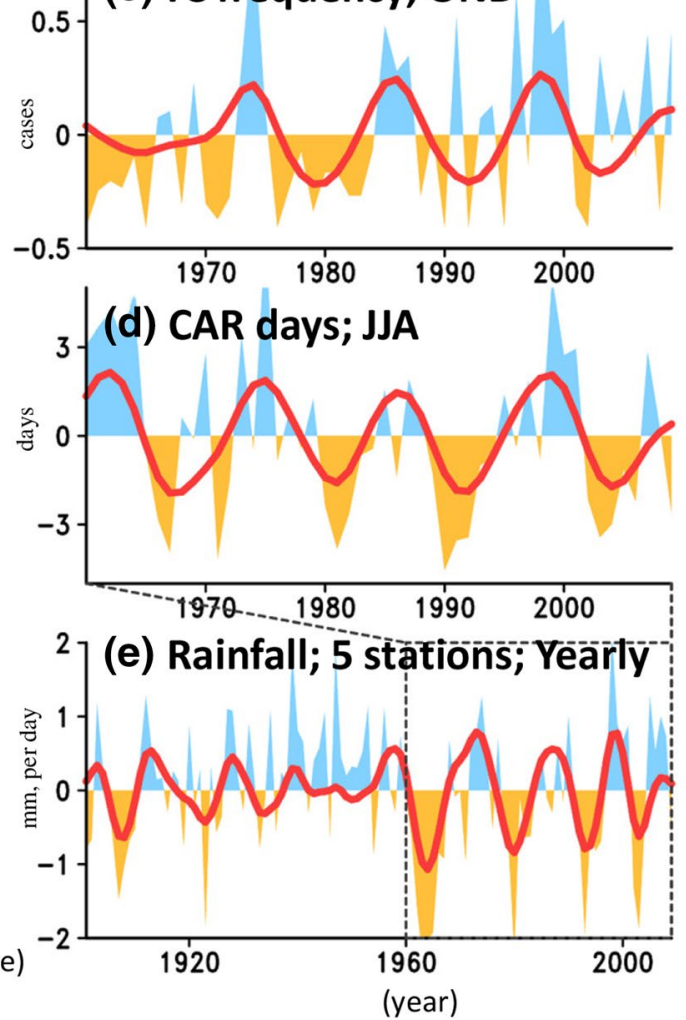

long-term precipitation records with more than 100 years of data are available from five stations (location given in Fig. 1a), providing useful information for the examination of the influence of the Pacific QDO prior to 1960. A visual examination of the annual precipitation derived from these five stations (defined as the "Taiwan precipitation index"; Fig. 1e) reveals that the QDO signal is persistent throughout the recorded period. Power spectrum analysis of the Taiwan precipitation index (Fig. 1f) reveals a significant peak within the QDO frequency band. For the post-1960 (1901-2009) period, the 10- to 20-year timescale variations explain approximately $29.6 \%$ (21.5\%) of the total precipitation variability in Taiwan (Fig. 1e), showing a significant spectral power (Fig. 1f).

Intrigued by the prominent quasi-decadal variability in Taiwan, as recorded in the instrumental data and weather events, we decided to examine the Pacific QDO's teleconnection impact on Taiwan and the associated changes in the basin-wide SST and atmospheric circulations, using the long-term reanalysis and SST data sets, starting in the twentieth century. To identify the cause of the regime change, we analyzed simulations of the twentieth century under different external forcings. The rest of the paper is arranged as following: Sect. 2 describes the data used for the analyses, Sect. 3 shows the observational analysis, Sect. 4 discusses the modeling results and Sect. 5 provides a conclusion.

\section{Data sources}

The instrumental precipitation records in Taiwan were provided by the Central Weather Bureau (CWB). For the construction of the long-term Taiwan precipitation index shown in Fig. 1e, we used 5 stations (Taipei, Taichung, Tainan, Hengchun and Taitung) with precipitation 


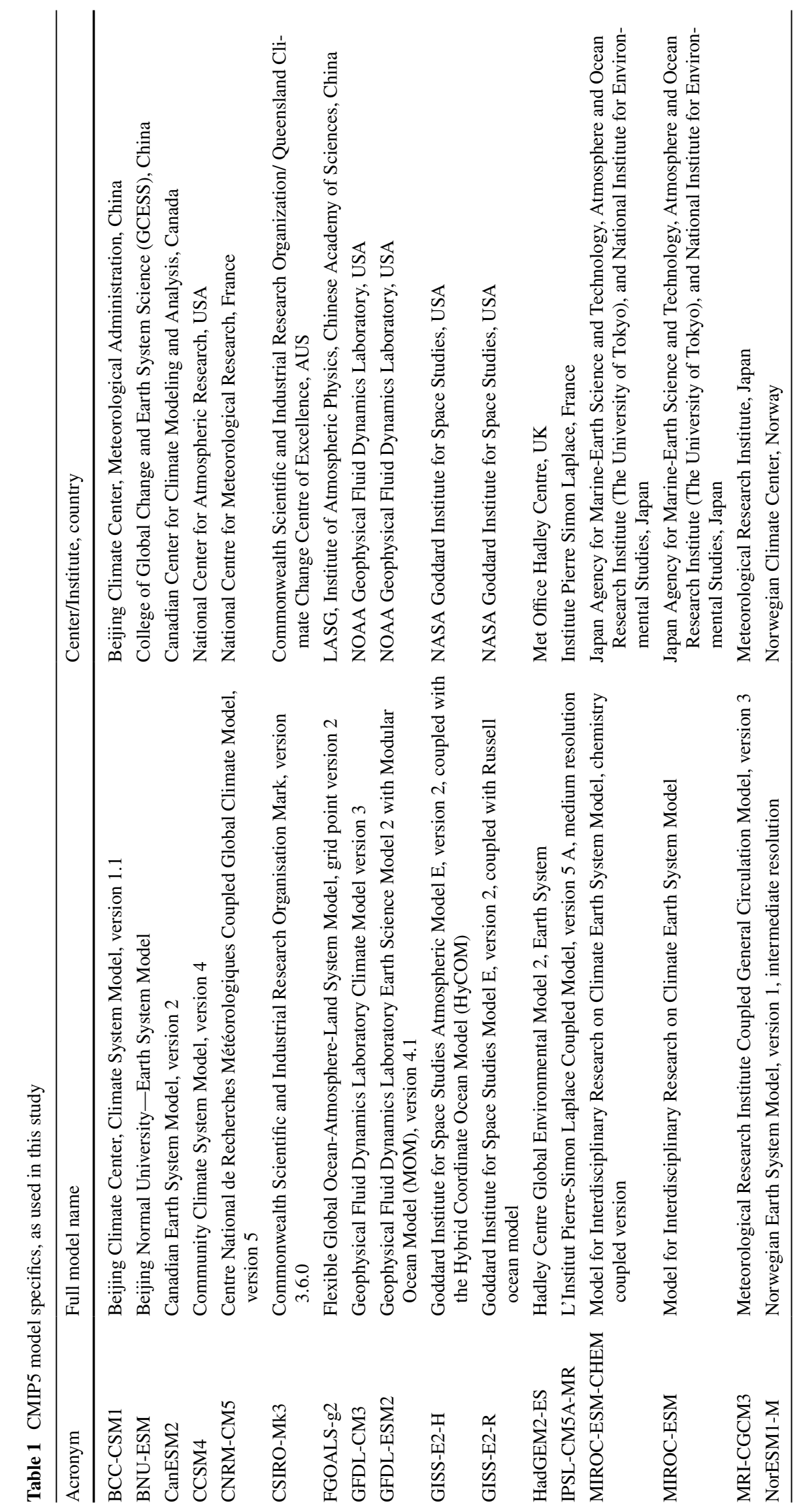


records starting from 1901. The Joint Typhoon Warning Center (JTWC) typhoon record was used for the data shown in Fig. 1c. For the observed SST, we used the National Oceanic and Atmospheric Administration (NOAA) Extended Reconstructed Sea Surface Temperature (ERSST) V3b dataset, starting in 1854 with a $2^{\circ}$ spatial resolution (Smith et al. 2008). Unless otherwise indicated, the analysis used the annual mean for all variables.

Additionally, we used two retrospective reanalysis datasets to depict the global atmospheric circulation and precipitation: the version-2 Twentieth Century Reanalysis (20CR) data (Compo et al. 2006, 2011) and the European Centre for Medium-Range Weather Forecasts (ECMWF) global reanalysis products for the twentieth century (ERA-20C) (Poli et al. 2016). The data of 20CR (ERA-20C) covers 1871-2012 (1900-2010). Based on large ensembles, 20CR (ERA-20C) utilized a coupled Atmosphere/Land-surface/Ocean model to assimilate surface observations of sea level pressure (surface pressure) to produce the atmospheric conditions. In the ERA-20C, the observed surface marine winds were also assimilated. However, due to the lack of upper-level observations prior to 1948 to validate the atmospheric circulation, we analyzed the two reanalysis datasets together in order to examine the consensus of our results. The precipitation output of 20CR and ERA20C is an ensemble of multiple simulations forced by the observed sea ice, surface temperature, and pressure conditions. The precipitation from 20CR over the tropical landmasses has been shown to outperform the more comprehensive NCEP-DOE Reanalysis 2 (Lee and Biasutti 2014).

For regime-change-attribution purposes, we adopted the ensemble mean of 16 CMIP5 (Coupled Model Intercomparison Project Phase 5) models forced by three different external forcings: (a) Historical (including all transient anthropogenic and natural forcings; hereafter ALL), (b) HistoricalNAT (only including natural forcings; NAT), and (c) HistoricalGHG (only including forcings from long-lived greenhouse gases; GHG). Here, the selection of the 16 CMIP5 models is based on data availability (1850-2005) among all three experiments: Historical, HistoricalNAT and HistoricalGHG; these are listed in Table 1. According to the power spectrum analysis shown in Supplementary Fig. S1, most of the simulations produced interannual to interdecadal variabilities, including a QDO peak for the two target time series (i.e., Taiwan precipitation and Niño4 SST) in the present work. These QDO signals are simulated by different forcings and will be compared to clarify the possible cause of the regime change.

\section{Observational analysis}

The Pacific QDO resembles the ENSO (El Niño Southern Oscillation) SST anomalies but features a broader warm/ cold tongue, with the maximum amplitude occurring in the Niño4 region (White and Tourre 2003; Wu et al. 2003; White and Liu 2008). It is loosely interchangeable with the North Pacific Gyre Oscillation, which has an energetic quasi-decadal frequency (Di Lorenzo et al. 2015). Following Wang et al. (2011), we calculated the Niño4 SST index from the ERSST data within the domain of $160^{\circ} \mathrm{E}-150^{\circ} \mathrm{W}, 5^{\circ} \mathrm{S}-5^{\circ} \mathrm{N}$ for the depiction of the Pacific QDO. By comparing the Taiwan precipitation index and Niño4 SST anomalies in Fig. 2 (both of which were bandpass-filtered by 10 - to 20 -years), significant negative correlations between the two appear to be most pronounced after $1960(\mathrm{r}=-0.75$, significant at $\mathrm{p}$-value $<0.1$, with the degree of freedom $=5$ after accounting for the bandpass filtering); this suggests increased (reduced) precipitation in Taiwan during the negative (positive) phase of the Pacific QDO. However, such a striking out-of-phase relationship between the Taiwan precipitation index and Niño4 SST did not exist in the pre-1960 period.

\subsection{Stationarity issues}

To examine the extent to which the changing relationship between Taiwan's precipitation and the Pacific QDO is due to the sampling variability, we tested the significance of the changing relationship using the non-filtered data following the methods of Gershunov et al. (2001); this is shown in Supplementary Figs. S2 and S3. There, we determined the 11-, 15-, 21-, and 31-year running correlations between the Taiwan precipitation index and Niño4 SST,

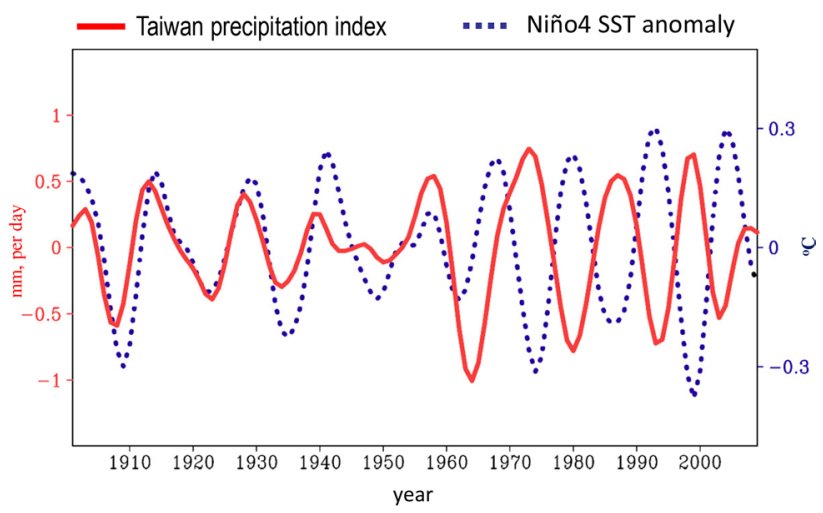

Fig. 2 The 10- to 20-year bandpass filtered precipitation in Taiwan from 5 hundred-year stations (defined as the Taiwan precipitation index; red solid line) and the annual Niño4 sea surface temperature (SST) anomalies (blue dotted line) 
and these running correlations reveal consistent regime changes (from positive correlations to negative correlations) that occurred around the 1960s. The significance test was carried out through the application of a bootstrapping scheme that simulated 500 pairs of correlated white noise time series mimicking the distribution of the Taiwan precipitation index and Niño4 SST. The standard deviations for the 21-year and 31-year windows pass the $95 \%$ significance test (using Table 1 of Gershunov et al. 2001), while the 11-year and 15-year windows pass the $90 \%$ significance test. We further computed the multitaper method (MTM) of spectral coherence and phase difference, using the unfiltered Taiwan precipitation index and Niño4 index, for two different periods: 1901-1950 (pre-1960) and 1960-2009 (post-1960). As shown in Supplementary Fig. $\mathrm{S} 4$, the decadal bands with significant coherence are present in both periods. However, the phase corresponding to the maximum coherency at the quasi-decadal frequency is different: i.e., there was a more in-phase relationship during 1901-1950 versus an out-of-phase relationship during 1960-2009. These analyses suggest that the observed change in the relationship between the Taiwan precipitation index and Niño4 index (Pacific QDO) is likely not an artifact of stochastic processes. Accordingly, the ensuing analysis uses data filtered for the QDO regime in the 10to 20-year passband.

\section{Correlation Maps}

Taiwan precip. index \& SST anomalies
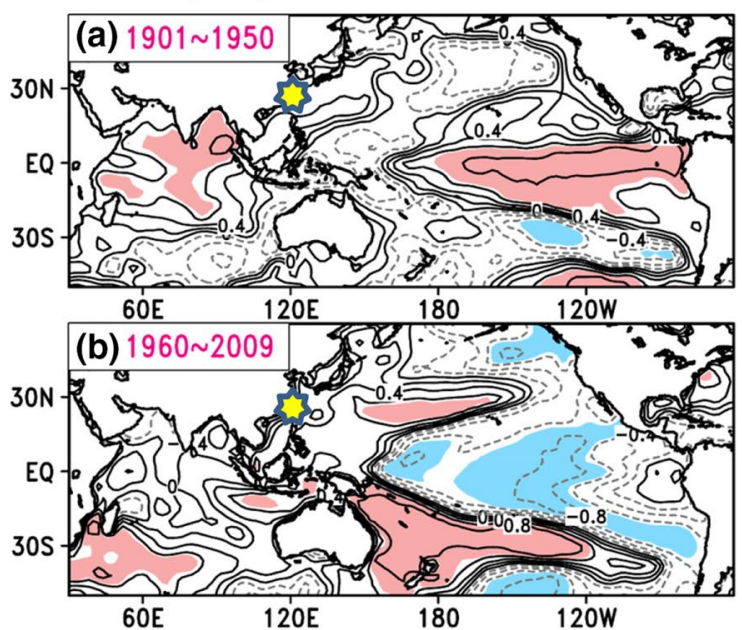

Taiwan precip. index \& streamfunction (20CR)
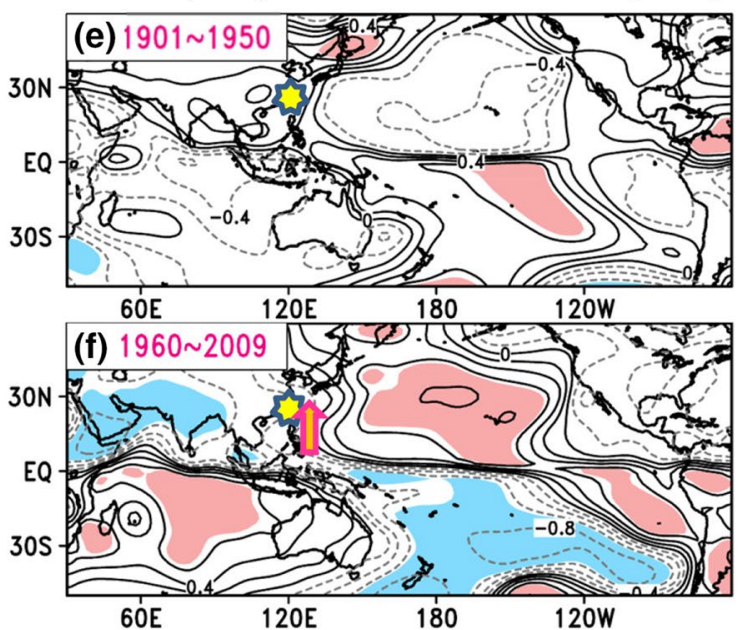

Fig. 3 One-point correlation maps between the 10- to 20-year bandpass-filtered Taiwan precipitation index and SST anomalies for two time periods: a 1901-1950 and b 1960-2009. The significant positive (negative) values, at $\mathrm{p}<0.1$, are shaded in pink (blue). The yellow
- Niño4 \& SST anomalies
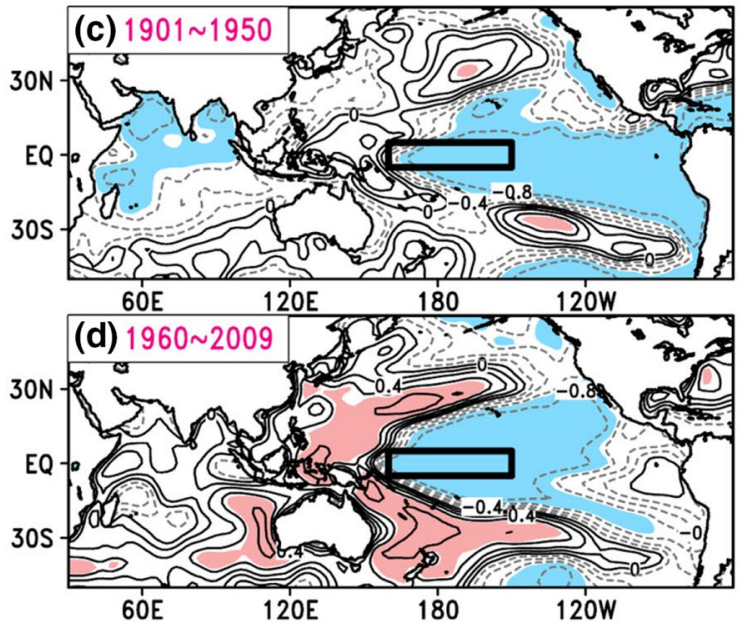

- Niño4 \& streamfunction (20CR)
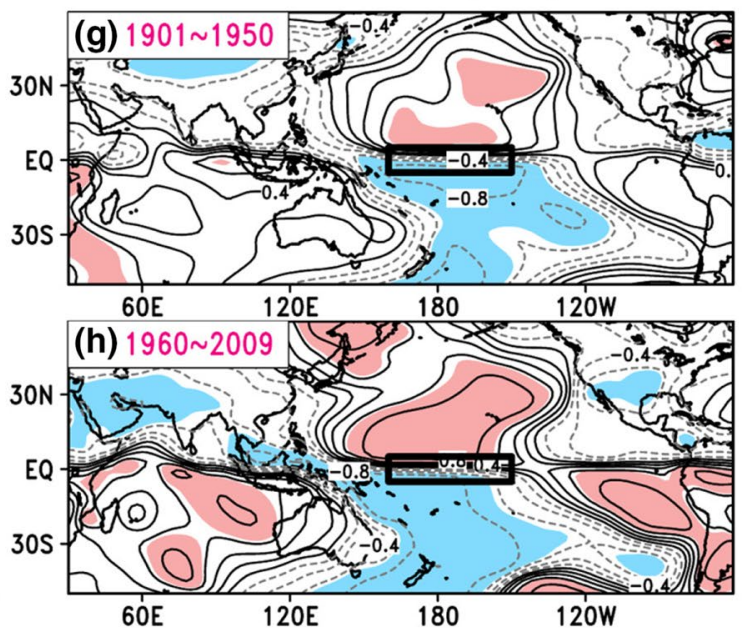

star marks the location of Taiwan. c, d Similar to $\mathbf{a}, \mathbf{b}$ but correlated with the bandpassed Niño4 SST (sign reversed, location outlined). e-h Same as a-d but for the 850-hPa streamfunction extracted from 20CR. The orange arrow in $\mathbf{f}$ indicates the southerly wind anomaly 


\subsection{The diagnoses}

The fluctuating correlation between the Taiwan precipitation index and Niño4 index is intriguing, as it suggests a change of the Pacific QDO's influence in the far western region of the Pacific Basin. To substantiate this inference, Fig. 3 shows the correlation map of the bandpass-filtered SST with the Taiwan precipitation index for two periods: 1901-1950 (pre-1960) and 1960-2009 (post-1960). The correlation between the Taiwan precipitation index and the Pacific QDO's SST pattern was positive in the pre-1960 period (Fig. 3a) but was then reversed, showing a distinct negative relationship over the Niño4 region (Fig. 3b). The post-1960 SST pattern bears some resemblance of that delineated by Hsu and Chen (2011) for the 10- to 20-year variability in the northern summer. Next, we constructed similar maps of SST anomalies correlated with the Niño4 index (sign reversed) in Fig. 3c, d. The results portray a consistent cold-tongue-like structure in both periods, suggesting that the underlying dynamics of the Pacific QDO had not changed, at least in the central and eastern Pacific sectors. What has changed is the associated regional SST variation over the western Pacific and northern Indian Ocean, i.e., the SST there was colder (warmer) in the cold (warm) phase of Niño4 before 1960 but has been warmer (colder) in the cold (warm) phase of Niño4 since then.

In correspondence with Fig. 3a-d, the associated change of the low-level atmospheric circulation was examined by computing the correlation maps of the $850-\mathrm{hPa}$ streamfunction. It appears that the Taiwan precipitation index was strongly connected to an anticyclonic anomaly in the western Pacific after 1960 (Fig. 3f) but was not before 1960 (Fig. 3e). The consequence of this circulation difference is reflected by the low-level southerly flow after 1960 (indicated by the arrows), which increases the moisture supplied to Taiwan. Likewise, Fig. 3g, h depict a post-1960 intensification of the North Pacific subtropical high (associated with the Pacific QDO), whose western extension would enhance the southerly flow near Taiwan. To validate the 20CR analysis (Fig. 3e, f), we also examined ERA20C. The results derived from ERA20C (Fig. 4) are consistent with those from 20CR, suggesting that (1) the Taiwan precipitation index was strongly connected to an anticyclonic anomaly in the western Pacific after 1960 (Fig. 4a, b), and (2) the North Pacific subtropical high associated with the Pacific QDO has intensified since 1960 (Fig. 4c, d). Based on these results (Figs. 3, 4 and Supplementary Figs. S3-4), one could draw a preliminary conclusion that the Pacific QDO's influence on the western Pacific underwent a drastic change in the 1960s, and the resultant local climate impacts were depicted by the annual precipitation in Taiwan.

Further analysis was carried out by computing the sliding correlations of the filtered Niño4 index (sign reversed) with SST (Fig. 5a) and precipitation (Fig. 5b, c), averaged across the latitudinal zone of Taiwan $\left(22^{\circ}-25^{\circ} \mathrm{N}\right)$. As shown in Fig. 5a, the local SST correlation near Taiwan (at approximately $120^{\circ} \mathrm{E}$ ) has changed from being negative in the pre-1960s period to predominantly positive after that.

\section{Correlation Maps}

Taiwan precip. index \& streamfunction (ERA20C)

- Niño4 \& streamfunction (ERA20C)
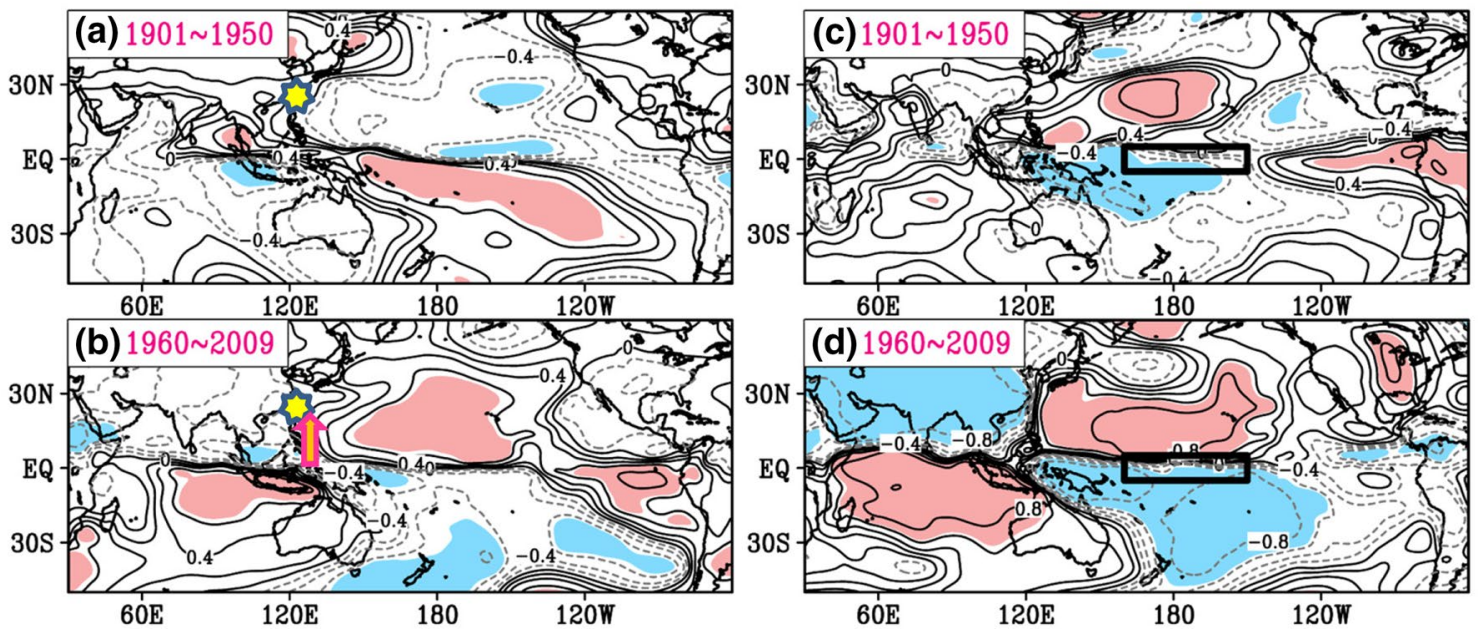

Fig. 4 Similar to Fig. 3e-h, but for ERA-20C 


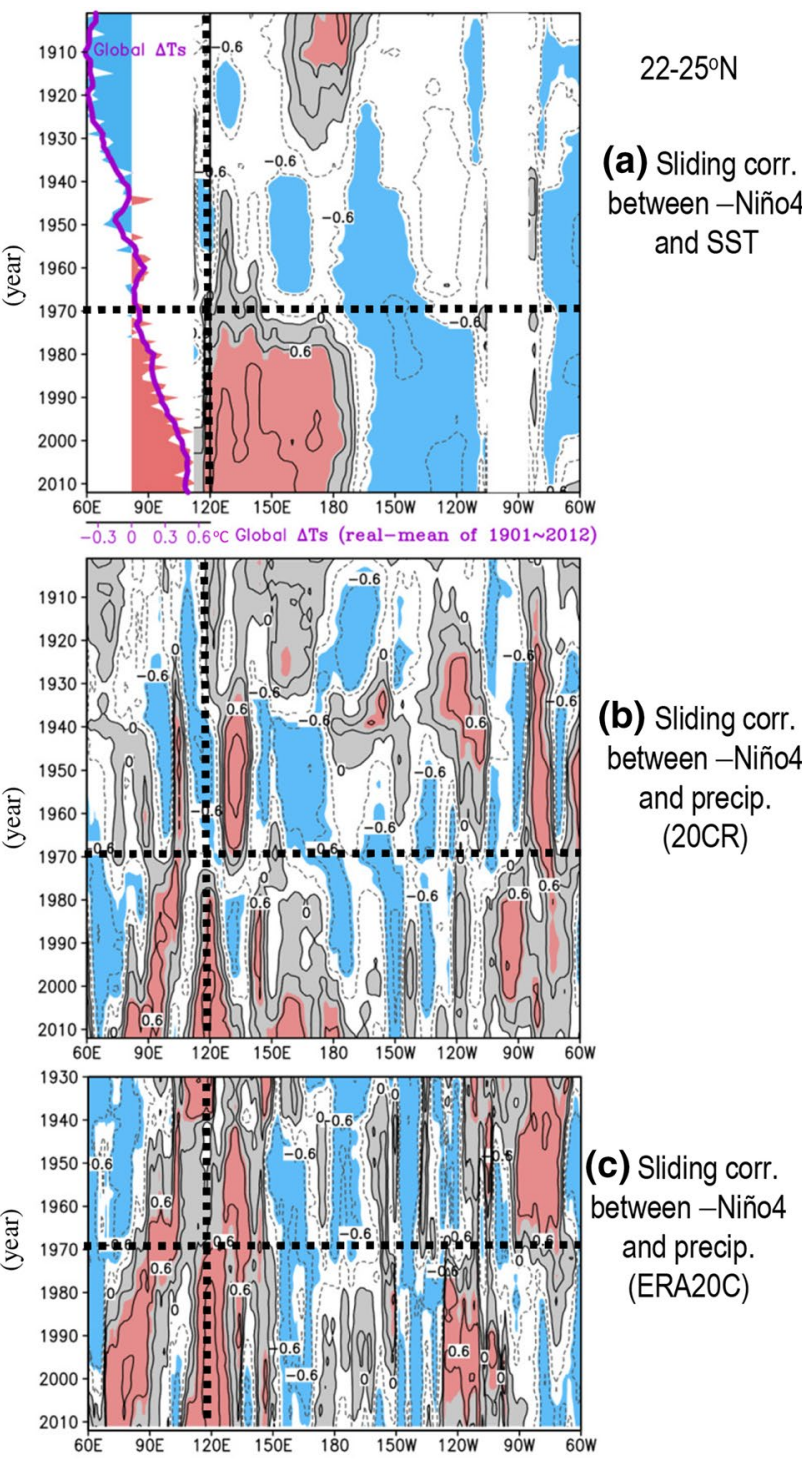

Fig. 5 a Sliding correlations between the bandpass-filtered Niño4 SST (sign reversed) and SST within a 30-year window from 1901 (indicating 1872-1901) to 2012 (indicating 1983-2012), averaged across the latitudinal zone of Taiwan $\left(22-25^{\circ} \mathrm{N}\right)$. The significant positive (negative) values, at $\mathrm{p}<0.1$, are shaded in pink (blue). b, c Same as a but for the 20CR and ERA20C precipitations, respectively. The global mean surface temperature anomaly $(\Delta \mathrm{Ts})$ time series (shaded curve) and its 10-year running mean (purple line) is plotted at the right side of (a). The location of Taiwan is indicated by the thick dotted lines at $120^{\circ} \mathrm{E}$

The SST shift covers most of the subtropical western North Pacific, which is consistent with Fig. 3c, d. Here, the change of precipitation in relation to Niño4 (sign reversed) was computed from the precipitation of the 20CR (Fig. 5b) and ERA20C (Fig. 5c) datasets. Both of the results of Fig. 5b, c show that Taiwan's precipitation changes transitioned into a regime with significant negative correlation with Niño4 in the post-1960 period. Together, the results in Fig. 5 imply that the westward expansion of warmer (colder) SSTs in the northwestern Pacific during the negative-phase (positivephase) Pacific QDO has become more robust, and this has enhanced the link between the Pacific QDO and the QDO in Taiwan. Notably, the two reanalyses did reveal a more consistent QDO signal in Taiwan after 1960, though neither reanalysis dataset captured the pre-1960 precipitation over Taiwan (Supplementary Fig. S5). This does not necessarily negate the quality of the data, however, as this observed feature can also be interpreted as being due to the change of the local responses to the Pacific SST at approximately 1960 affecting the regional precipitation.

\subsection{Possible dynamics}

Several noteworthy features are revealed in Fig. 5. The Western Pacific warming is known to affect the precipitation in climate model projections (Brown et al. 2015). As inferred from previous studies examining the change of the North Pacific subtropical high under global warming (Li et al. 2012; He and Zhou 2015), it is plausible that the regional SST response to global warming can influence the western extension of the North Pacific subtropical high. To illustrate this point, we overlaid the global surface temperature (GST) anomalies in Fig. 5a to compare it with the sliding correlations. The cooler period, before 1940 (warmer period after 1970), coincides with the predominant negative correlations (positive correlations) between the northwestern Pacific SST and Niño4 SST, while the period of the warming slow-down (between 1940 and 1970) is concurrent with the transition of the correlation regimes. This result echoes the observation of $\mathrm{Li}$ et al. (2012) and He and Zhou (2015), who stated that global warming has increased the average northwestern Pacific SST, and this adds to the thermal contrast between the land and ocean, further enhancing the westward extension of the subtropical anticyclone. In other words, precipitation in Taiwan underwent the aforementioned change of the local SST coupled to the Pacific QDO, owing to its proximity to the North Pacific subtropical high extension.

The next question is that of the extent to which the Pacific QDO may have changed during the mid-twentieth century. As an independent measure of Taiwan's 


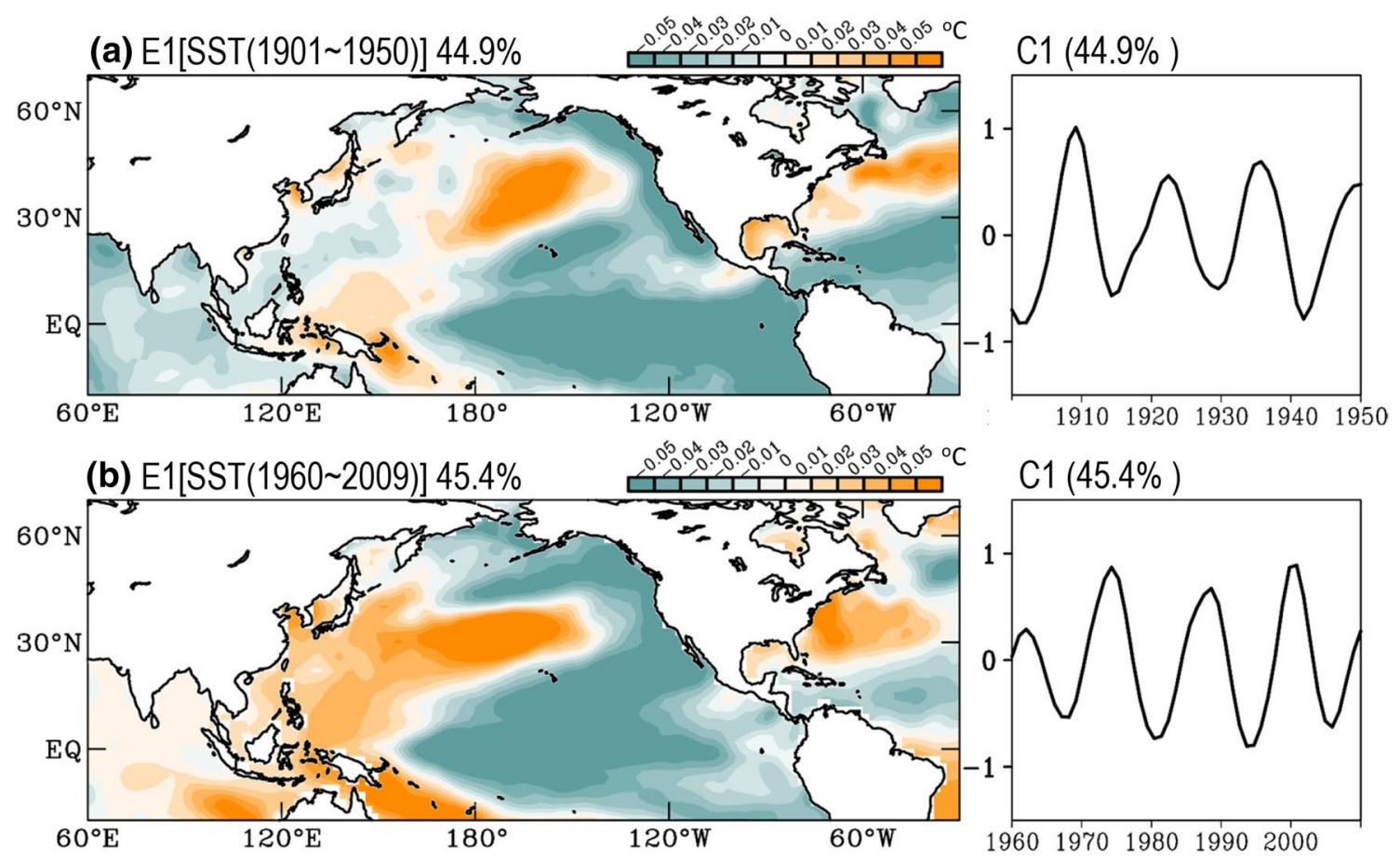

Fig. 6 First mode of the Empirical Orthogonal Function (EOF) analysis of the bandpass-filtered SST for the two periods: a 1901-1950 and b 1960-2009

precipitation connection, we applied an Empirical Orthogonal Function (EOF) analysis to the bandpass-filtered SST for the two periods: 1901-1950 and 1960-2009; their first mode is shown in Fig. 6. A few changes in the SST pattern are noticeable, and the most relevant one is the increased variation (warming, as in Fig. 6) over the western Pacific. This change echoes the observed increase in the area-averages of the Pacific SSTs over $110^{\circ} \mathrm{E}-150^{\circ} \mathrm{E}, 20^{\circ} \mathrm{S}-40^{\circ} \mathrm{N}$, which have shown a linear increase of $\sim 0.8^{\circ} \mathrm{C}$ during 1901-2009 (not shown). Warming in the western Pacific likely increases the sensitivity of air-sea interactions, promoting a more energetic reaction to SST variation (e.g., Wang et al. 2013), and this process can affect the impact of the Pacific QDO. Located near the boundary between the East Asian continent and the Pacific Ocean, the change in SST variations near Taiwan can alter (or shift) the circulation and precipitation distributions, affecting the local weather (e.g., Wang et al. 2016).

\section{Regime-shift attribution from CMIP5 simulations}

Given that the timing of the regime change coincides with the noticeable anthropogenic warming influence, we further examined the potential effect of global warming. Figure 7 shows the correlation map based on the filtered Niño4 index (sign reverse) and the eddy Ts (with its zonal mean removed) simulated by the 16 CMIP5 models from the Historical, HistoricalNAT and HistoricalGHG experiments. We used the eddy Ts to highlight the east-west thermal contrast, which is important for the formation of the teleconnection pattern (otherwise, the CMIP5 simulations would show a similar oscillation phase in the QDO for the SST between the western Pacific and eastern Pacific, especially for the post-1960 period; not shown). As revealed in Fig. 7a, the ensemble mean of the historical simulations depicts a regime change towards an enhanced relationship between the negative phase of the Pacific QDO and western North Pacific warming after 1960s. This simulated feature agrees with what was revealed in the observed eddy SST analysis (Supplementary Fig. S6), which shows a regime change similar to that seen in Fig. 3c, d. The details of the capability of the model to simulate SST variability are referred to in Li and Xie (2014), Wang et al. (2014), and Wang et al. (2015).

Next, we compared Fig. 7a with the corresponding correlation maps of the HistoricalNAT (Fig. 7b) and HistoricalGHG (Fig. 7c) simulations. The HistoricalNAT simulations do not reveal any westward shift of the SST 


\section{(a) Correlation map based on -Niño4 and eddy Ts from Historical experiment}
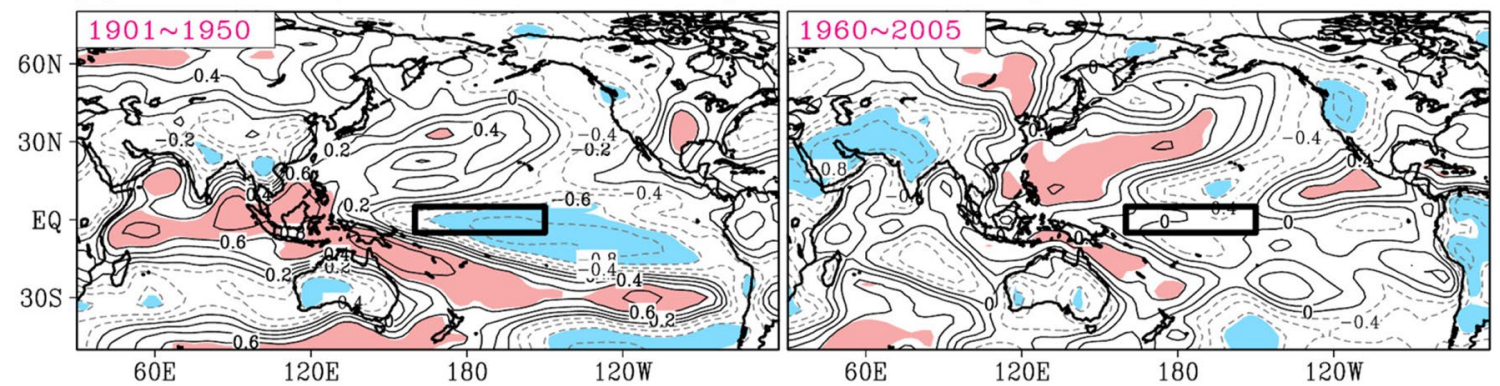

(b) Correlation map based on -Niño4 and eddy Ts from HistoricalNAT experiment
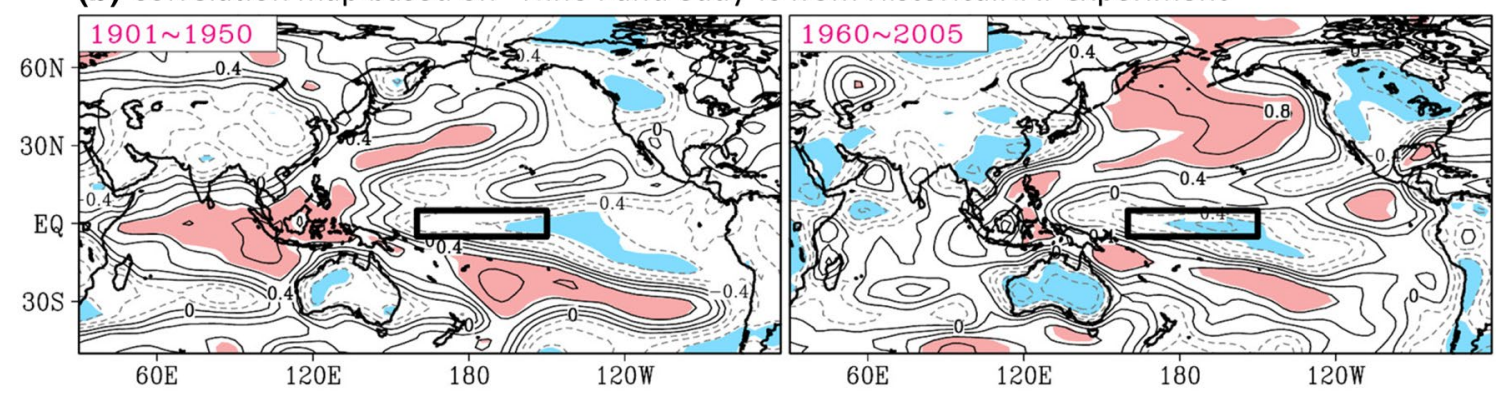

(c) Correlation map based on-Niño4 and eddy Ts from HistoricalGHG experiment
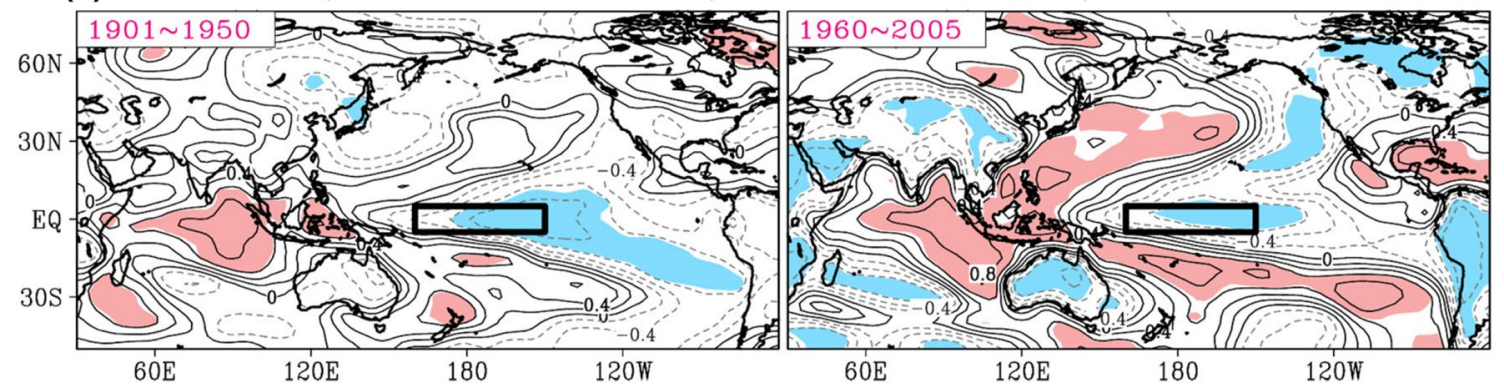

Fig. 7 The correlation map based on the 10- to 20-year bandpass-filtered Niño4 index (sign reverse, location outlined) and eddy Ts (with its zonal mean removed) simulated by the 16 CMIP5 models from the a Historical, b HistoricalNAT and c HistoricalGHG experiments for

pattern, whereas the HistoricalGHG simulations (Fig. 7c) reproduced the westward shift of the SST pattern that was depicted by Historical simulations. To clarify this finding, we also followed the example of Fig. 5 to compute the 30-year sliding correlations of the filtered Niño4 index (sign reversed) with the simulated eddy Ts averaged across the latitudinal zone of Taiwan $\left(22^{\circ}-25^{\circ} \mathrm{N}\right)$; these are shown in Fig. 8a, b for the HistoricalNAT and HistoricalGHG simulations, respectively. The relationship of the westward expansion of the warmer SST anomalies in the northwestern Pacific with the negative phase of the Pacific QDO becomes increasingly robust in the HistoricalGHG the two periods: 1901-1950 and 1960-2005. The models including in the ensemble are listed in Table 1. The significant positive (negative) values, at $\mathrm{p}<0.1$, are shaded in pink (blue)

simulations (Fig. 8b) but does not in the HistoricalNAT simulations (Fig. 8a), suggesting a GHG impact.

Following the example of Fig. 4c, d for the depiction of the teleconnection pattern change, Fig. 9 shows the correlation map between the filtered Niño4 index (sign reverse) and the $200-\mathrm{hPa}$ vorticity ( $\zeta$, shaded), superimposed with wind circulation (streamline), which were derived from the CMIP5 Historical (Fig. 9a), HistoricalNAT (Fig. 9b) and HistoricalGHG (Fig. 9c) simulations. An apparent westward shift in the Pacific-North American (PNA) teleconnection is revealed in the Historical simulations after 1960 (Fig. 9a). This westward shift in the PNA teleconnection is 

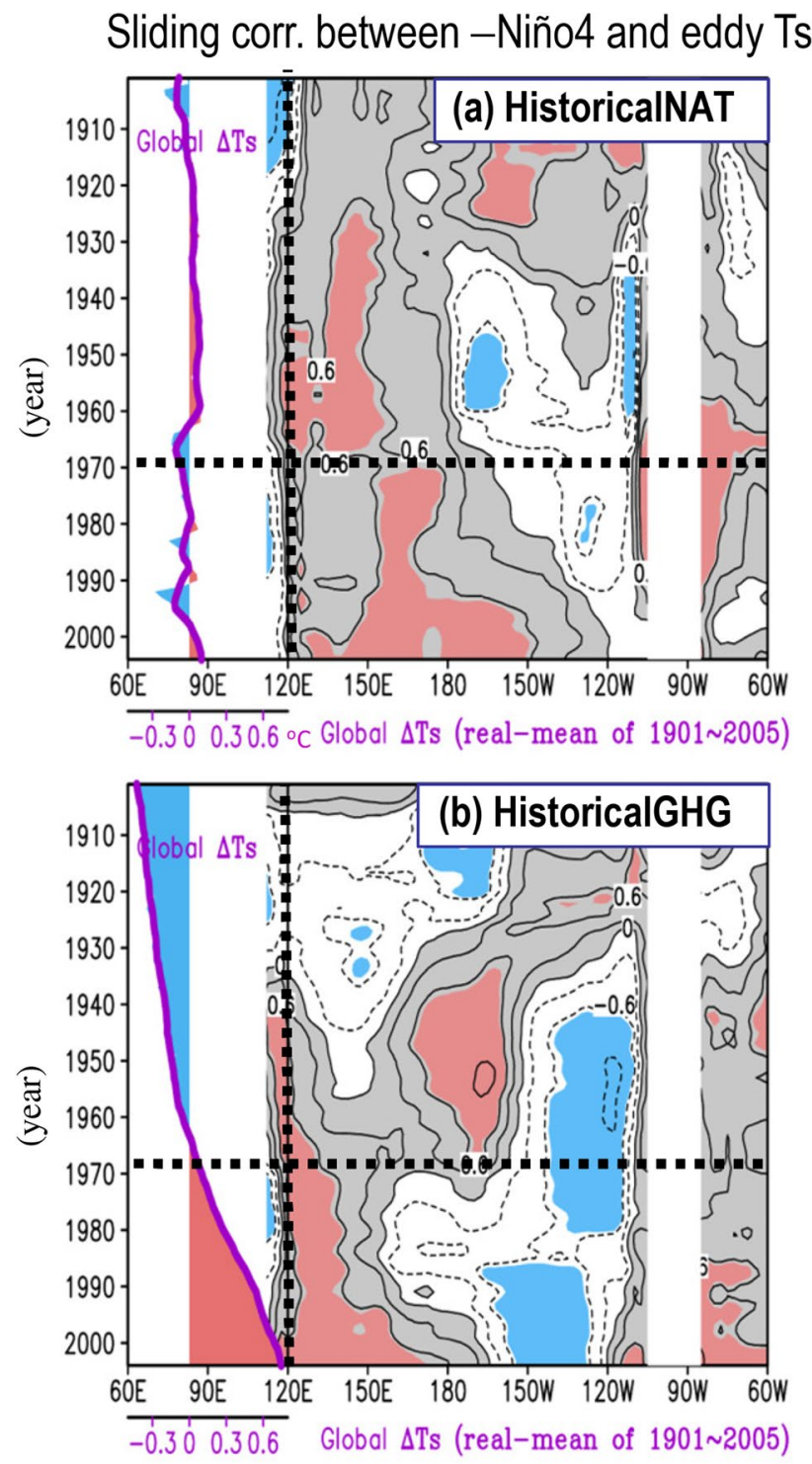

Fig. 8 Similar to Fig. 5, but for the 30-year sliding correlations of the filtered Niño4 index (sign reversed) with the simulated eddy Ts averaged across the latitudinal zone of Taiwan $\left(22^{\circ}-25^{\circ} \mathrm{N}\right)$ : a HistoricalNAT and $\mathbf{b}$ HistoricalGHG simulations

only captured by the HistoricalGHG simulations (Fig. 9c) but not by the HistoricalNAT simulations (Fig. 9b). The results of Figs. 7, 8 and 9 lend support to our previous finding, specifically that the relationship between the negative phase of the Pacific QDO and western Pacific warming after the 1960s is influenced by anthropogenic climate warming by way of the east-west extension of the Pacific QDO teleconnection.

\section{Concluding remarks}

The 110-year record of Taiwan's annual precipitation depicts a marked quasi-decadal variation and its fluctuating relationship with the Pacific QDO. The presented analyses indicate that (1) the Taiwan precipitation index exhibits a robust 10 - to 20 -year oscillation that complements the previous studies of the quasi-decadal variations in precipitation and different types of weather systems affecting Taiwan and (2) the relationship between the Taiwan precipitation index and the Pacific QDO has changed around the 1960s, with an increased and significant negative correlation. It was proposed that the increased SST in the western Pacific, associated with global warming, has modified the regional SST and precipitation signals around Taiwan associated with the western extent of the Pacific QDO teleconnection. This modification is likely caused by the enhancement of the North Pacific subtropical anticyclone, as the strengthened western extension of this system increases the meridional wind anomalies near Taiwan. As a result, the local SST variation around Taiwan (which affects moisture transport and precipitation) has become increasingly "reactive" or sensitive to the Pacific QDO in an out-of-phase manner. The CMIP5 simulations suggest that the GHGforced SST, precipitation, and circulation anomalies resemble the changes in the Pacific QDO's relationship with Taiwan's precipitation, indicating the contribution of global warming.

Given that the strengthened North Pacific subtropical anticyclone is linked to global warming, one might expect the out-of-phase relationship between Taiwan's precipitation anomalies and the Pacific QDO to continue. If this holds true, then monitoring the Pacific QDO from Niño4's low-frequency variation could help to anticipate the longterm fluctuations in the precipitation and weather systems of Taiwan. This implication deserves further exploration. 
(a) Correlation map based on -Niño4 and [ $\zeta, \mathrm{V}](200 \mathrm{hPa})$ from Historical experiment

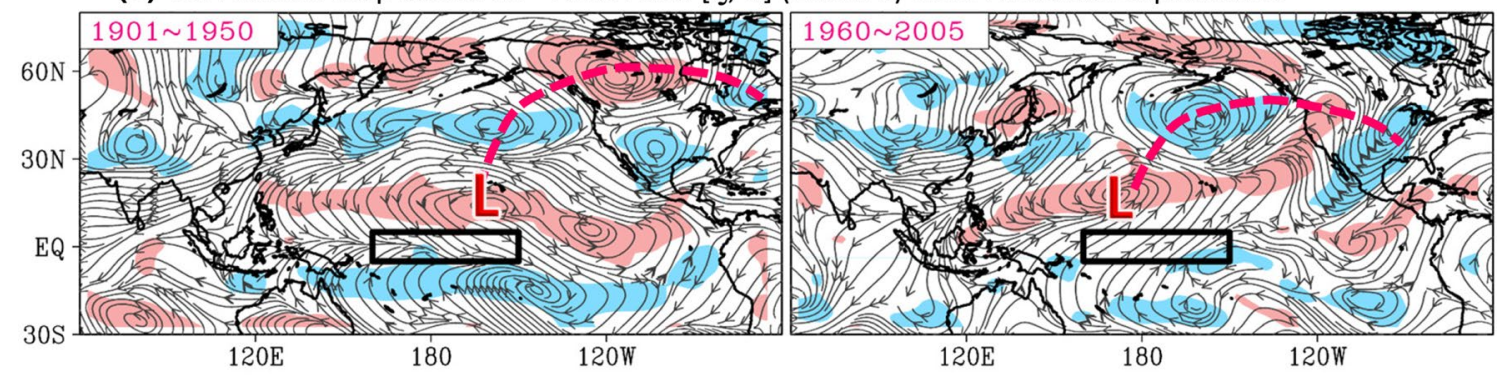

(b) Correlation map based on $-\mathrm{Niño} 4$ and $[\zeta, \mathrm{V}](200 \mathrm{hPa})$ from HistoricalNAT experiment

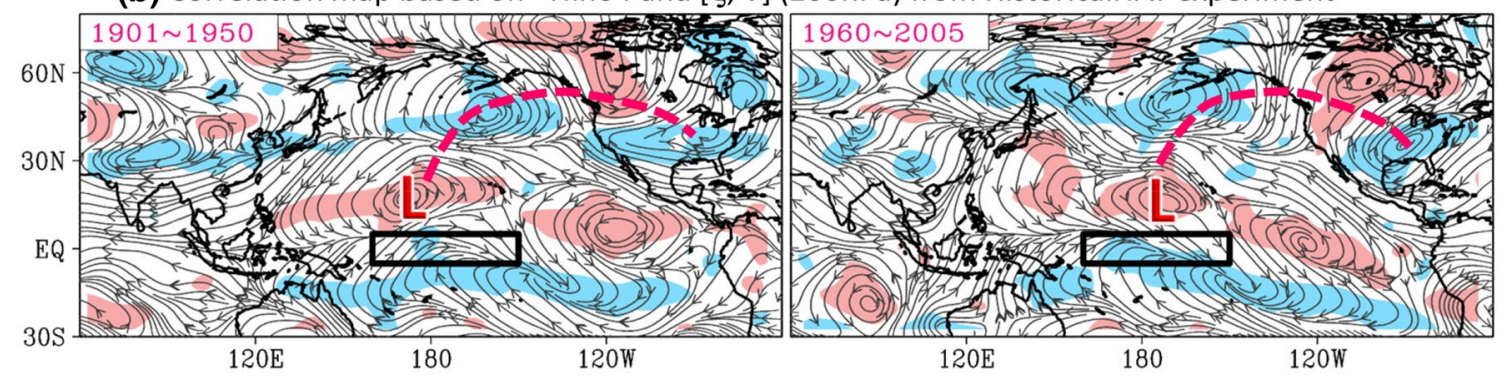

(c) Correlation map based on -Niño4 and [ $\zeta, \mathrm{V}]$ (200hPa) from HistoricalGHG experiment
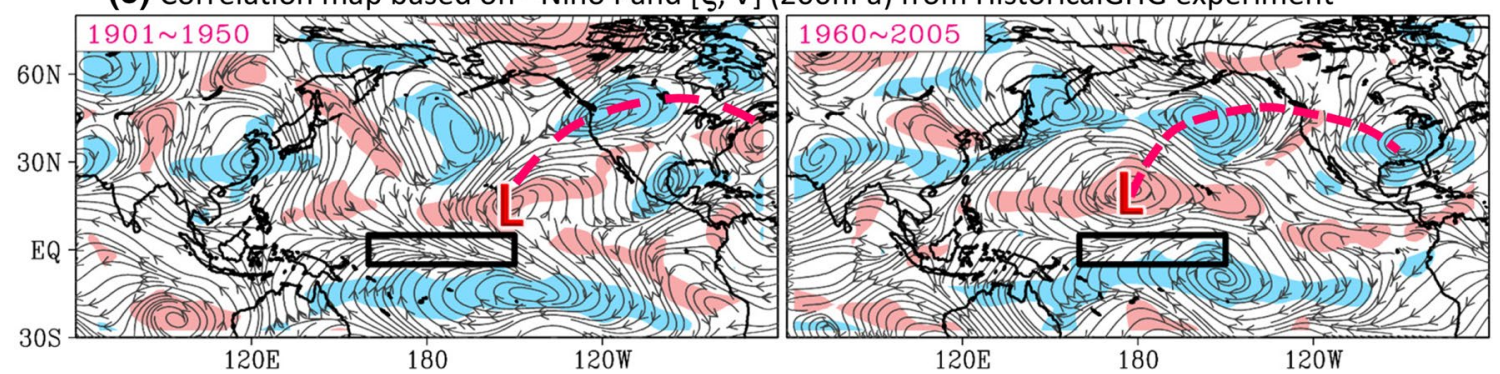

Fig. 9 Similar to Fig. 7, but for the correlation map based on the 10to 20-year bandpass-filtered Niño4 index (sign reversed, location outlined) and $200-\mathrm{hPa}$ vorticity ( $\zeta$, shaded) and related wind circulation (streamline) extracted from the CMIP5 a Historical, b HistoricalNAT and $\mathbf{c}$ HistoricalGHG simulations. The significant positive (negative)

Acknowledgements The authors thank the anonymous reviewers for their comments and suggestions, which greatly improved the manuscript. This research was supported by the Ministry of Science and Technology of Taiwan under MOST 105-2119-M-003-002 and MOST 105-2625-M-003-002. S.-Y. Wang was supported by 7-RCSEED01-002/RC-2709.

Open Access This article is distributed under the terms of the Creative Commons Attribution 4.0 International License (http://creativecommons.org/licenses/by/4.0/), which permits unrestricted use, distribution, and reproduction in any medium, provided you give appropriate credit to the original author(s) and the source, provide a link to the Creative Commons license, and indicate if changes were made.

\section{References}

Brown JN, Matear RJ, Brown JR, Katzfey J (2015) Precipitation projectionsin the tropical Pacific are sensitive to different types of SST bias adjustment. Geophys Res Lett 42:10856-10866 values, at $\mathrm{p}<0.1$, are shaded in pink (blue). The symbol " $L$ " represents the cyclonic circulation in the North Pacific that is related to the Pacific-North American teleconnection (linked by dashed line), as discussed in the manuscript

Chan JCL (2008) Decadal variations of intense typhoon occurrence in the western North Pacific. Proc R Soc A 464:249-272.

Chen JM, Chen HS, Liu JS (2013) Coherent interdecadal variability of tropical cyclone rainfall and seasonal rainfall in Taiwan during october. J Clim 26:308-321

Compo G, Whitaker JS, Sardeshmukh PD (2006) Feasibility of a 100year reanalysis using only surface pressure data. Bull Am Meteor Soc 87:175-190

Compo G P, Whitaker J S, Sardeshmukh P D, Matsui N, Allan R J, Yin X, Gleason B E, Vose R S, Rutledge G, Bessemoulin P, Brönnimann S, Brunet M, Crouthamel R I, Grant A N, Groisman P Y, Jones P D, Kruk M C, Kruger A C, Marshall G J, Maugeri M, Mok H Y, Nordli Ø, Ross T F, Trigo R M, Wang X L, Woodruff S D, Worley S J (2011) The Twentieth Century Reanalysis Project. QJR Meteorol Soc 137:1-28.

Di Lorenzo E, Liguori G, Furtado J, Schneider N, Anderson B T, Alexander M (2015) ENSO and meridional modes: a null hypothesis for Pacific climate variability. Geophys Res Lett. doi: 10.1002/2015GL066281.

Fan K, Liu Y, Chen H P (2012) Improving the Prediction of the East Asian Summer Monsoon: New Approaches. Weather Forecast 27:1017-1030. 
Gershunov A, Schneider N, Barnett T (2001) Low frequency modulation of the ENSO-Indian monsoon rainfall relationship: Signal or noise. J Clim 14:2486-2492

He C, Zhou T (2015) Responses of the western North Pacific Subtropical High to global warming under RCP4.5 and RCP8.5 scenarios projected by 33 CMIP5 models: The dominance of tropical Indian Ocean-tropical western Pacific SST gradient. J Clim 28(1):365-380

Hsu HH, Chen YL (2011) Decadal to bi-decadal rainfall variation in the Western Pacific: a footprint of the Pacific decadal variability in the South Pacific. Geophys Res Lett 38:L03703

Huang W R, Hsu H H, Wang S Y, Chen J P (2015) Impact of atmospheric changes on the low-frequency variations of convective afternoon rainfall activity over Taiwan. J Geophys Res Atmos 120:8743-8758

Hung C W (2013) A 300-year typhoon record in Taiwan and its relation with solar activity in the decadal variations. Terr Atmos Ocean Sci 24:737-743

Lee DE, Biasutti M (2014) Climatology and variability of precipitation in the twentieth-century reanalysis. J Clim 27:5964-5981

Li C (1998) The quasi-decadal oscillation of air-sea system in the northwestern Pacific region. Adv in Atmos Sci 151:31-40

Li G, Xie S (2014) Tropical biases in CMIP5 multimodel ensemble: the excessive equatorial pacific cold tongue and double ITCZ problems. J Clim 27:1765-1780

Li R C Y, Zhou W (2014) Interdecadal change in South China Sea tropical cyclone frequency in association with zonal sea surface temperature gradient. J Clim 27:5468-5480

Li W, Li L, Ting M, Liu Y (2012) Intensification of Northern Hemisphere subtropical highs in a warming climate. Nat Geosci 5(11):830-834.

Li R, Wang S Y, Gillies R R, Buckley B M, Truong L H, Cho C (2015) Decadal oscillation of autumn precipitation in Central Vietnam modulated by the East Pacific-North Pacific (EP-NP) teleconnection. Environ Res Lett 10:2024008

Lu MM, Lee CT, Wang B (2013) Seasonal prediction of accumulated tropical cyclone kinetic energy around Taiwan and the sources of the predictability. Int J Climatol 33:2846-2854

Poli P, Hersbach H, Dee DP (2016) ERA-20C: an atmospheric reanalysis of the twentieth century. J Clim 29:4083-4097
Smith TM, Reynolds RW, Peterson TC, Lawrimore J (2008) Improvements to NOAA's historical merged land-ocean surface temperature analysis (1880-2006). J Clim 21:2283-2296

Sun B, Wang H (2015) Inter-decadal transition of the leading mode of inter-annual variability of summer rainfall in East China and its associated atmospheric water vapor transport. Clim Dyn 44:2703-2722

Wang SY, Clark AJ (2011) Quasi-decadal spectral peaks of tropical Western Pacific SSTs as a precursor for tropical cyclone threat. Geophys Res Lett 37:L21810. doi:10.1029/2010GL044709

Wang S Y, Gillies R R, Hipps L E, Jin J (2011) A transition-phase teleconnection of the Pacific quasi-decadal oscillation. Clim Dyn 36:681-693

Wang SY, L'Heureux M, Yoon JH (2013) Are greenhouse gases changing ENSO precursors in the Western North Pacific? J Clim 26:6309-6322

Wang C, Zhang L, Lee S K, Wu L, Mechoso C R (2014) A global perspective on CMIP5 climate model biases. Nat Clim Change 4: 201-205

Wang G, Dommenget D, Frauen C (2015) An evaluation of the CMIP3 and CMIP5 simulations in their skill of simulating the spatial structure of SST variability. Clim Dyn 44: 95. doi:10.1007/s00382-014-2154-0

Wang S Y S, Lin Y H, Wu CH (2016) Interdecadal change of the active-phase summer monsoon in East Asia (Meiyu) since 1979. Atmosph Sci Lett 17:128-134

White WB, Liu Z (2008) Resonant excitation of the quasi-decadal oscillation by the 11-year signal in the Sun's irradiance. J Geophys Res-Oceans 113(C1):C01002

White WB, Tourre YM (2003) Global SST/SLP waves during the 20th century. Geophys Res Lett 30:1651

Wu L, Liu Z, Gallimore R, Jacob R, Lee D, Zhong Y (2003) Pacific decadal variability: the tropical Pacific mode and the North Pacific mode. J Clim 16:1101-1120

Zhao S, Yang S (2014) Dynamical prediction of the early season rainfall over Southern China by the NCEP Climate Forecast System. Weather Forecast 29:1391-1401 